Birlesik Dünya Arastırma

BD-CENTER

Innovasyon ve Yayıneılık Merkezi

\section{Global Journal of Sociology: \\ Current Issues}

Volume 10, Issue 2, (2020) 71-87

\title{
Scavenging for Ejiao's raw material and the extinction of donkeys in Nigeria
}

\author{
Muhammad Abdullahi Maigari*, Department of Sociology, Faculty of Social Sciences, Usmanu Danfodiyo \\ University, Sokoto, Nigeria
}

Umar Dantani, Department of Political Science, Usmanu Danfodiyo University, Sokoto, Nigeria

Muson Mohammed Yelwa, Department of Sociology, Al-Qalam University Katsina, Nigeria

Arafat Ibrahim, Department of Sociology, Gombe State University, Nigeria.

\section{Suggested Citation:}

Maigari, A. M., Dantani, U., Yelwa, M. M. \& Ibrahim, A. (2020). Scavenging for Ejiao's raw material and the extinction of donkeys in Nigeria. Global Journal of Sociology: Current Issues. 10(2), 71-87. https://doi.org/10.18844/gjs.v10i2.5102

Received July 15, 2020; revised September 13, 2020; accepted November 10, 2020.

Selection and peer review under responsibility Prof. Dr. Mustafa Gunduz, Cukurova University, Turkey.

${ }^{\circ} 2020$ Birlesik Dunya Yenilik Arastirma ve Yayincilik Merkezi. All rights reserved.

\begin{abstract}
This paper examines the increasing presence of merchants in Northern Nigeria purchasing donkeys in large numbers beyond domestic consumption in parts of Nigeria that eat its meat and drink its milk. Also, this paper examines the economic and social effects on donkey users, especially in rural areas. Theoretically, this paper has adopted a Marxist explanation as the framework of analysis to analyse the trade between China and Nigeria. Methodologically, this paper employed a phenomenological research design under qualitative research where data were obtained from in-depth interviews and key informant interviews in Kebbi, Zamfara and Sokoto States with owners, marketers and users of donkeys in the selected states. This paper found that the areas surveyed witnessed an influx of marketers, foreign and domestic, who were into the business of trading donkeys or its skin. This paper also found that as a result of the high demand for donkeys, the owners preferred to sell their donkeys than domesticate them, because of the mouth-watering price from exporters. The study revealed that the majority of the villagers were not aware of what the exporters used the donkeys for. This is because the Chinese traders or their agents have not established manufacturing in Nigeria where the donkey serves as a raw material for the production of a traditional medicine called ejiao. This paper concludes that villagers are not aware of the cumulative effects of the unprecedented demand for donkey's skin to produce ejiao and this is evident in the shrinking population of donkeys in Nigeria. This paper recommends that if trading donkeys is not controlled, there is a tendency that the donkey would become extinct in Nigeria, which will have adverse effects on the life of rural dwellers who rely on it for transportation of goods and domesticate it as an asset.
\end{abstract}

Keywords: China, donkey's skin, ejiao, globalisation, Nigeria, trading.

* ADDRESS FOR CORRESPONDENCE: Muhammad Abdullahi Maigari, Department of Sociology, Faculty of Social Sciences, Usmanu Danfodiyo University, Sokoto, Nigeria.

E-mail address: kariyoma2@yahoo.com 
Maigari, A. M., Dantani, U., Yelwa, M. M. \& Ibrahim, A. (2020). Scavenging for Ejiao's raw material and the extinction of donkeys in Nigeria. Global Journal of Sociology: Current Issues. 10(2), 71-87. https://doi.org/10.18844/gjs.v10i2.5102

\section{Introduction}

The donkey is among the animals that are used as a means of transportation in Africa and parts of Asia. It is also commonly found in Australia, Northern Nigeria and Niger Republic. Donkeys are found in large numbers and are used for different purposes prior to the arrival of European colonialists in the 18th century to Africa who introduced vehicles and other mechanised farm equipment. The inhabitants of Northern Nigeria are mostly farmers and use the donkey as a beast of burden to draw water from a tube well in the Sahel Desert. In adaption to the Sahelian vegetation, which is characterised by hot temperature, low rainfall, few grasslands and rivers to feed livestock, the donkey is among the animals that can endure the aforementioned geographical conditions of the arid zone. For transportation and farming, the donkey is regarded as one of the simplest means of carrying people and farm inputs and output from home to farm and vice versa in the desert areas in Asia and Africa. Starkey and Fielding (2004), Blench (1995) and John et al. (2017) have strengthened the above assertion and stated that in Nigeria, donkeys are widely distributed in the Northern part of the country, possibly introduced by caravan trading across the Sahara. They are mainly used for traction and farming activities. Additionally, they play a significant role in easing the lives of human beings. It was principally used for transporting millet and maize and other farm produce from farms to the markets where roads were almost non-existent in rural areas of Africa. However, due to the Islamic religious beliefs in Northern Nigeria which prohibit the consumption of its milk and meat, traders purchase donkeys (16,000 annually) and ship to the eastern and southern parts of Nigeria where both meat and milk are consumed.

Similarly, at the dawn of the 21st century, there were about one million donkeys and mules at work in South Africa (Fernando, $\mathrm{n} \mathrm{d}$ ). The donkey belongs to the horse family, but unlike the horse, it is small in size with short legs. Also, unlike the horse, it can travel long distances with a very heavy load without showing any signs of fatigue (Talla \& Song, 2014). These features give donkeys the advantage over other animals which are in the same family to be used for transporting heavy loads and people. However, in countries like China, donkeys are used for different purposes other than transportation and agricultural purposes. A study conducted by the Donkey Sanctuary found that the donkey's skin is used in the manufacturing of alternative medicine. The need for raw materials for the production of ejiao, which is the donkey's skin, has necessitated the pharmaceutical industries in China to go beyond the shores of China in search of the skin to supplement their insufficient domestic supply. Substantiating the above assertion, the Donkey Sanctuary revealed that the Chinese's demand for ejiao would require 2.5-4.5 million donkey skins/year; yet, they are only able to get 1 million/year and thus the threat of unsustainable utilisation and skyrocketing prices for donkeys is higher as demand has surpassed the supply because of the skin (Donkey Sanctuary, 2017). Explaining further, donkey skin is used in producing alternative medicine, which China has been famous for. The rising demand for non-orthodox medicine produced from donkey skin necessitates Chinese pharmaceutical companies to focus their attention on Africa in search of raw material (donkey skin). An empirical study in Africa showed that more than two millennia ago donkey-hide glue (colla corii asini) was used in Chinese apothecary (Kohle, 2017).

Ejia or 'E-glue', as it is known in the Chinese language, consists of gelatin extracted from donkey's skin when it is boiled in water. According to Chinese traditional belief, it strengthens the blood cells, controls excessive bleeding and increases the working of vital fluids in human body. Additionally, it has the capacity to restore the vigour of depleted patients or taken as a life-enhancing tonic to strengthen vitality and promote health. Biomedical and clinical trials confirm the hematopoietic (blood cellproducing) effect of donkey-hide gelatin (DHG) (Kohle, 2017). These health benefits made ejiao a coveted medicine in China and in countries where there are a significant number of Chinese.

It has been observed that the largest factory for the production of Ejiao is located in Dong'e area of China. The company Dong'e Ejiao Corporation Limited (DEEJ) was reported by ECONEWS Portal as the world's biggest manufacturer of gel made from donkey's skin. The company has expanded its operation and production because of the increase in demand for the products, especially among the 
middle class in China. This is the reason ejiao is regarded as one of the luxury good in China because the upper- and middle-class Chinese cherish to include it in their daily meals as a demonstration of wealth or social class. The report stated that roughly, every year, DEEJ used to process the skins from one million donkeys and produce about $63 \%$ of the ejiao in circulation in the world markets. Similarly, the yearly profits made by DEEJ witnessed a 10\% increase in 2018 compared to the 2017 profits. The report concluded that DEEJ and similar companies that are into the production of ejiao have contributed to the rise in its value (ECONEWS Portal, 2018).

Similarly, statistics shows that the largest companies that are into the production of ejiao are in China. Supplier Discovery (2021), an online website for the sales of Chinese products, showed that there are 14 companies in China that into production and marketing of ejiao. They are Weihai Baihe Biology Technological Co., Ltd. located in the Weihai, Shandong; Hebei Lang Mei Biotechnology Co., Ltd. located in Shijiazhuang, Hebei; Shandong Fupai Ejiao Co., Ltd. located in Jinan, Shandong; Shandong Hongjitang Pharmaceutical Group Co., Ltd located in Jinan, Shandong; Chongqing TOP Oil Purifier Co., Ltd. located in Chongqing, Chongqing; Dalian Reyes Import \& Export Co., Ltd. located in Dalian, Liaoning; Shijiazhuang Hualiu Health Care Products Sales Co., located in Shijiazhuang, Hebei; Shandong Zhanhua Jonnicfood Co., Ltd., located in Shandong, Shandong; Sino Pharmaceutical Technology Co., Ltd. located in Jining, Shandong; Changzhou Chuangke Drying Granulating Equipment Co., located in Changzhou, Jiangsu; Hefei Joye Import \& Export Co., Ltd. located in Hefei, Anhui; Luan Jinyu Metal Printing \& Can Co., Ltd. located in Liuan, Anhui; Shenzhen Zonsin High-Tech Co., Ltd. located in Shenzhen, Guangdong; and Shanghai Brightol International Co., Ltd. located in Shanghai, Shanghai (Supplier Discovery, 2021).

Brooke USA (2018) has provided a detailed explanation for the rise in the production of ejiao and demands for donkeys in different parts of the world. One of the main causal factors for the expansion of the ejiao is that the demand has exploded over the course of the last decade as the Chinese middle class has expanded. Similarly, even though ejiao products are expensive, more Chinese can now afford them. Therefore, to meet the demands from the manufacturers and users of the products, the donkey population in China has collapsed by $76 \%$ since 1992. A palliative measure was taken where ejiao companies had set up donkey breeding schemes in China in an attempt to breed the species on a scale sufficient to meet local demand. However, due to the areas result of the long gestation period of donkeys, which they give birth once a year, breeders have not been able to satisfy the demand from within China. This is why ejiao companies have turned to Africa and Latin America to satisfy their demand for this product.

\section{Statement of the problem}

A survey carried out by Brooke USA (2018) found that the production of ejiao has devastating effects on the families who depend on donkeys for survival. Kenya's Agricultural and Livestock Research Organisation reported that 159,631 donkeys were slaughtered for their skins $(8.1 \%$ of the population) in 2018. Similarly, the report further states that about 1,000 donkeys are slaughtered in Kenya every 24 hours, and more than 300,000 a year. The report concluded that donkeys in Kenya could vanish by 2023 because they are regularly killed illegally and often slaughtered in the bush or street just outside their owners' property. The report has explained the level of the trade for donkeys in Kenya which is not for domestic consumption of the Kenyans but for export as raw materials to China for the production of ejiao.

In the same vein, the activities of poachers for donkey have increased the market value of donkeys beyond the financial strength of poor farmers in Africa, Asia and Latin America who use them for farming activities. Poaching affects the livelihood of rural dwellers who use the animal to access water and farm use (World Veterinary Association Fact Sheet, 2018). It also undermines the survival of many dependent communities, especially in Latin America, Africa and Asia, which depend on it for some of their activities. It has been observed that mass slaughtering of donkeys for their skins is one the factors that contributes to environmental pollution from abandoned carcasses. This is compounded by 
Maigari, A. M., Dantani, U., Yelwa, M. M. \& Ibrahim, A. (2020). Scavenging for Ejiao's raw material and the extinction of donkeys in Nigeria. Global Journal of Sociology: Current Issues. 10(2), 71-87. https://doi.org/10.18844/gjs.v10i2.5102

inappropriate waste disposal at the legal slaughterhouses because only the skin is of interest to the marketers and middlemen of pharmaceutical industries that manufacture ejiao. Thus, the rising demand risks outstripping supply districts in West Africa (World Veterinary Association Fact Sheet, 2018). This report has identified the social and economic effects of the decreasing population of donkeys and the rise in the price which attracted criminals to start stealing and illegally kill them for the purpose of their skin.

For example, a study conducted by Golley and Jaiving (2018) has found that poaching donkey's skin has reached an alarming rate in Niger Republic, Tanzania and South Africa, as well as Nigeria. In these countries, donkeys' owners used to wake up in the morning to find their donkeys slaughtered and dumped without their skin. Additionally, Brooke USA (2018) found that the population of donkeys worldwide has been nose-diving as a result of the trade of donkey skin for the manufacturing of ejiao, which does not have an effect on the population of donkeys but on rural communities who have been using the animals for other purposes, especially in rural agrarian communities in developing countries.

Based on the above discourse and statement of the problem, the objective of this paper is to examine the nature of trade of donkey's skin in Nigeria. In this regard, the study has answered the following research question: What is the nature of donkey skin trade in Nigeria. The rationale for this study is that the magnitude of trading (globalisation of trade) donkeys in Nigeria is a result of growing concern across the globe over the decreasing population of donkeys. This would enable the individuals who both possess and use donkeys for agricultural purposes to be aware whether their locality is affected by the demands for donkey's skin in China. This study would be of significance to nongovernmental organisations, both local and international, which protect donkeys and other animals from extinction because of their economic and ecological importance.

\section{Reviewed literature: global trade of donkeys for their skin}

Bennett and Pfuderer (2020) observed that that the demand for donkey hide for gelatin used in traditional Chinese medicine, called ejiao, has increased greatly over recent years, resulting in high and rapidly increasing prices. This has put pressure on donkey populations globally and has led to theft and illegal trading of donkeys, resulting in concerns for donkey welfare and the livelihoods of those who rely on donkeys, especially in developing countries. In response to the increasing demand and criticisms, China has introduced a modern donkey farming system to address the shortage of donkeys which is the source of raw material for ejiao. However, despite the establishment of the modern farming system for donkeys, the result indicates that it will take at least 10-15 years or more for new donkey farming systems to be able to supply the demand for hides. This implies that the prices of donkeys and donkey hide will continue to increase with continued thefts and illegal trade. This will have further negative impacts on donkey welfare and on the livelihoods of those who rely on donkeys. This signifies that Chinese ejiao producers will continue to try to source donkey hide from around the world, putting even greater pressure on donkey populations globally. The work of Bennett and Pfuderer (2020) has explained the magnitude of the demand for donkey's skin and indicates that the Chinese merchants would continue to explore different parts of the world where donkeys are found to feed their pharmaceutical companies that manufacture ejiao.

Celermajer and Wallach (2019) carried out an empirical study in Australia on the fate of wild donkeys. The researchers found that in the era of globalisation of trade and communication, donkeys have become a commercial commodity susceptible to exploitation in the feverish international trade and trafficking in their skins for the industrial production of the traditional Chinese medicine ejiao. The study explained that as a result of international trade, either legal or illegal, donkeys are now the target of the suppliers of raw materials for the Chinese manufacturers of ejiao. The study has established a correlation between international trade and exportation of donkeys to Asian countries, particularly China. 
A study has shown that apart from donkeys, there are other animals whose existence on earth is threatened by global poaching, especially from the Asian countries. Elephants are among the animals whose global demand are soared and enriched by marketers in the global market. According to Vira, Ewing and Miller (2014, p. 3), in Africa, $5 \%-7 \%$ of the elephant population are killed annually by poachers and traders. At the hands of wholesalers, ivory price had increased from USD \$5/ $\mathrm{kg}$ in 1989 to USD $\$ 2,100 / \mathrm{kg}$ in China in 2014, while retail prices were more than to USD $\$ 30,100 / \mathrm{kg}$. The huge amount of money realised from the animal necessitates the formation of a trafficking organisation, which transports and sells ivory along a very long chain of supply which is complex for security operatives to trace along the corridors of international frontiers between Africa and the destination of wholesalers and retailers in Asia (Vira et al., 2014).

A study conducted in China showed that it was not only African donkeys that face extinction but also Chinese donkeys, which are threatened by the demands for consumption and medicinal purpose. Lei et al. (2007) conclude that there was an increase in the demand for donkey's meat because of its high nutritional value, and it is considered as a green food in China in addition to pharmaceutical need for the production of ejiao. Therefore, the demand for donkey's skin and meat has encouraged the rearing of donkeys to meet the shortfall in supply. However, the major weakness in the work of Lei et al. (2007) is that it was a laboratory-based study, not social research. Also, the study has not related the effects poaching on the decrease in the population of donkeys due to high demand for raw materials for the manufacturing of ejiao by pharmaceutical industries in China. However, the study has examined the effects of high demands for donkey skin which is used in manufacturing ejiao and how it leads to the decrease in the population of donkeys in the world. It has also examined the consequences of the decrease in the population of donkeys on the livelihood of people because majority of the rural dwellers in the areas surveyed relied on it as a means of transporting human beings and goods.

The scale of the trade between Australia and China could lead to the extinction of all species of donkeys from the face of the earth. The study explained the devastating effects of the decrease in the population of donkeys in rural communities which rely on it for livelihood. This is compounded by the lack of any form of legislation and control for the trade and slaughter of donkeys in many countries (Kohle, 2017). The study shows that the phenomenon that hovers around the donkey is not peculiar to developing countries in Africa. However, what is peculiar here is the lack of proper mechanisms for control to check the activities of foreign merchants of donkey skin. These merchants transact their business of donkey trade freely in rural areas, which has led to the increase in the importation to donkeys in China. For example, in China, from 2014-2019, a minimum four million donkeys were slaughtered for the production of ejiao. This accounts for the killing of donkeys in the hundreds every week, solely for the purpose of ejiao production. The consequences of such a high demand for donkeys are that many of the donkeys do not live for more than 3 years before they are slaughtered and skinned. Additionally, statistics have shown that the total population of donkeys in China had reduced by $52 \%$, from 12.7 million in 1954 to 6.03 million in 2013, which decreased at a yearly rate of 3\%-5\% (Kohle, 2017).

Based on the above consequences, in Burkina Faso, for example, as a result of the rapid decrease in the population of donkeys, the government has banned the export of live donkeys and donkey hides to China. It has regulated donkey slaughter within its borders for the protection of the population. BBC reported that in 2015 donkey-hide exports rose from 1,000 in the first quarter to 18,000 in the fourth quarter in Burkina Faso. The number reached 65,000 in the first half of 2016, whereas the country had an estimated 1.4 million donkeys. This indicates that if the trend continues, in less than 5 years the entire donkey population in the country would be exported to China.

Following Burkina Faso, BBC (2016) reported that the Niger Republic government banned donkey export to China. It exported 27,000 donkeys to China in 2016 and 80,000 in 2017. Driven by the high demand from China, the price of one donkey hide rose from \$4 USD several years ago to \$50 USD in 2017, while a live donkey went up from \$34 USD to \$100-145 USD. Donkeys are mainly used for 
Maigari, A. M., Dantani, U., Yelwa, M. M. \& Ibrahim, A. (2020). Scavenging for Ejiao's raw material and the extinction of donkeys in Nigeria. Global Journal of Sociology: Current Issues. 10(2), 71-87. https://doi.org/10.18844/gjs.v10i2.5102

transportation and occasionally as a source of meat in Niger. However, a report showed that the export and slaughter of a large number of donkeys threatened the local donkey population due to the demand for their products. A study in Cameroon showed that there was a demand for donkeys due to perceived medicinal value of some products or the social status associated with them (World Wide Fund for Nature/Dalberg, 2012).

Therefore, the above studies indicated how the global demand for raw materials for the production of alternative medicine threatens the existence of animals. Both in China and Africa, the findings show that the increasing demand for donkeys for medicinal purpose threatens the population of the animal. About five million skins are needed to produce 5,000 tonnes of ejiao (which is consumed each year in China). Before the soaring rate in production of ejiao in China, there were 11 million donkeys. In 2016, there were only five million donkeys in China, and the growing demand for the medicine has halved the population of donkeys. The shortfall in supply has been compelling Chinese manufacturers of ejiao to search for raw materials beyond their shores. Most of these raw materials are supplied from African countries like Niger, Nigeria, South Africa and Burkina Faso. However, as stated earlier, Niger Republic and Burkina Faso have banned the export of donkeys to China as part of measures to protect the animal from extinction.

However, Kenya has an important commercial relationship with China, which permits the exportation of donkey hide to China. Within the span of 1 year, donkeys have decreased from 1.8 million in 2008 to 900,000 in 2017. The price of donkeys rose to 150 Euros per head, a figure that local farmers could not afford (Asia News, 2018). The findings of this study signify the continual decrease in the population of donkeys in Africa. This has a direct effect on its price in places where the local people use it for transportation and farming purposes. Similarly, if the trend continues unchecked, there is a tendency that donkeys will be wiped out from the face of the earth.

A cross-sectional study was conducted in five counties in Kenya by Carder et al. (2019) on the emerging trade in donkey hide. The study assessed both opportunity and threat for communities. The researchers adopted mixed methods of data collection that is household survey questionnaire, focus group discussion and key informant interviews (KII). Donkey hides are used to make traditional Chinese medicine called ejiao. The demand for ejiao is extremely high, whereas the global donkey population is on the decline. Africa's donkey population is considered a key source for the trade, with Kenya being highlighted as the major victim. The study found that in Kenyan donkeys vitally contribute to people's livelihoods. The researchers conclude that that smallholder farmers are choosing to sell their donkeys for an instant boost in income, but in the long term this is unlikely to be a sustainable livelihood option. The above study has examined the consequences of global trading in donkey, especially in rural areas where majority of the inhabitants rely on it for different purposes.

Similarly, an empirical study was conducted in Australia by Wallach, Lundgren, William, Ripple and Ramp (2018). The study found that the skins of wild and domestic donkeys (Equus asinus) are being traded and marketed worldwide to produce ejiao for the Chinese medicine industry. The growing demand is driving crime, animal cruelty and poverty, and some of the skins are traded along the same networks that traffic in cites listed species. The work examined several factors related to the trade in donkey skin and the effects of illegal trade on both donkey and human beings who benefit from its existence.

In this regard, Bennett and Pfuderer (2019) anticipated that the quest for ejiao raw materials from China in developing countries would spur illegal activities related to the trade in donkey skin. Nonetheless, international trade in donkey hide is likely to continue to play an important role, at least in the short term, and a number of countries have given permission for donkey slaughter houses to be built. Trade can contribute to the supply of donkey hides, but it will not be possible to meet the current demand. Therefore, prices are likely to continue to increase. The researchers conclude that there is currently a shortfall in the supply of donkey hides that cannot be met either within China or from other countries. For this reason, fake ejiao products and illegal activities are likely to continue to characterise donkey hide and ejiao markets. The prediction of this study is correlated with what was 
Maigari, A. M., Dantani, U., Yelwa, M. M. \& Ibrahim, A. (2020). Scavenging for Ejiao's raw material and the extinction of donkeys in Nigeria. Global Journal of Sociology: Current Issues. 10(2), 71-87. https://doi.org/10.18844/gjs.v10i2.5102

found in the areas where this study was conducted in Northern Nigeria, particularly increase in the criminal activities in the theft of donkeys.

In line with the above, the Global Initiative against Transnational Organised Crime (2020) reported that East Asia plays a significant role in the trafficking of high-profile wildlife products, such as ivory and rhinoceros horn. However, less known is the trade in donkey skin. The hides are processed in East Asia for use in traditional Chinese medicine, ejiao. Plummeting donkey populations have led many African states to ban the export of these products, with Kenya being the latest to do so. However, the report stated that theft and cross-border smuggling of donkeys in East Africa is still rife, and there seems to be a significant risk of an emerging organised illicit trade that would circumvent the bans now covering much of Africa. The report suggested that a regional approach to combatting donkey smuggling may be necessary to safeguard the animals and the vital role they play in subsistence lifestyles across East Africa and beyond.

A study was conducted in Botswana by Matlhola and Chen (2020) on donkey trade. The researchers adopted a telecoupling framework to examine trade on donkey skin between Botswana and China. The study established that the donkey population is decreasing in many countries because of economic development, urbanisation and increased demand for donkey hides in China. The study further found that the donkey population in Africa has rapidly declined recently due to supplying China with donkey hides for the production of highly demanded and legalised traditional medicine called ejiao. Based on the consequences of the trade, some African countries, including Botswana, banned the export of donkey hides as an effort to protect the animal from disappearing from the earth.

Despite the ban, the sales of donkey's hides have become highly profitable for both exporters from Africa and importers in China largely due to a huge demand in donkey hides from China. The sudden increase in demand for donkey hides has motivated criminals to focus on donkeys. In South Africa, for example, they are stolen and brutally killed in order to obtain their hides. To reduce illegal trade on donkey hide, the South African government has legalised the exportation of donkeys based on certain conditions including only when the donkey was first sold by the legitimate owner and must be slaughtered in a registered Abattoir (National Prosecuting Authority (NPA) South Africa, 2017).

Explaining the economic significance of the donkey, the Donkey Sanctuary revealed that the increasing illegal trade in donkey hides has devastating effects on local communities in developing countries. Most of the estimated 44 million donkeys worldwide are working animals, with a significant number in economically developing African nations (Donkey Sanctuary, 2017). The money earned by each working animal could support between 5 and 20 family members. Having a donkey stolen means owners are without the animal they need most for earning a living, affecting access to food, water and education (Jackson, 2019). The trade between African countries and China is detrimental to Africa, and China's engagement in Africa has negative consequences for economic growth and development. This is evident in China's presence in all parts of Africa in search of raw materials, particularly primary goods with little market value. This encouraged Africa's continuous reliance on the importation of manufactured goods, remaining an exporter of raw materials, which aggravates the resource sources in the continent (Carmignani \& Chowdhury, 2012). Similarly, over the last 2 years Kuo (2017), global trade in donkey skins has emerged, as ejiao has become popular among middle-class Chinese who use it as an anti-ageing agent, an aphrodisiac, a cure for insomnia or poor circulation and other healthrelated benefits. At least 1.8 million donkey hides are traded per year in China which are imported from different parts of the world, mostly Africa.

Critiquing the trade relationship between Africa and China, the effects of the trade relationship between China and sub-Saharan African countries on commodity export were likely to be stronger than for SSA commodity import to China for three main reasons. First, the trading transactions segment of the economy in commodity exporting economies. Second, China is a much larger fraction of that trade in commodity exporters than in commodity importers. Finally, export prices tend to pass in a similar direction as economic activity in China for commodity exporting countries, and in the 
opposite direction for commodity importing countries (Derek, Jorge, Paul, Pedr \& Dirk, 2015). Expansion of the manufacturing sector in China has overstretched domestic production of raw materials which has created the need for the importation of raw materials from foreign countries. A study found that domestic demands in China are capable of affecting imports from trading partners, but the impact differs among countries. China's trade ties with low-income and developing economies have risen markedly in recent years, dominated by fuel, minerals and metals (Chen \& Nord, 2017). Although the findings of Chen and Nord (2017) have not focused on trade in donkeys hide, the study has examined the growing interest of China in Africa with its accompanying effects, negative and positive. However, regarding the issue of donkey trading, it is negative; because there is a tendency that if the current rate at which donkeys are exported to Chinese manufacturers of Ejiao is not curtailed, then there would be a day when donkeys would not be found in Africa.

In sum, the presence of Chinese manufacturers in SSA could be described as a seller, buyer, supporter and investor. As a seller, China exports cheaper products to Africa, which save money for consumers; as a buyer, due to China's import, the price of Africa's products increased significantly. However, statistics showed the contrary, China's export to Africa shared less than $3 \%$ of its total export to the world, which is much lesser than its exports in 2005 to Asia (56.8\%), Europe (18.4\%), North America (16.2\%) and Latin-America (3.5\%) (Bo, 2018). A cross-sectional study carried out in Cameroon revealed that the value of manufactured goods imported to Cameron has increased exponentially in 4 years, i.e., between 2001 and 2005. However, there was a decrease in the exports of raw materials to China from the same direction which caused trade deficits for the Cameroonian economy. Based on the foregoing facts, unequal trade relations have slowed the growth of the manufacturing sector and locked the country in the production of primary goods (Khan, Baye \& Tange, 2009).

In line with the above, it could be deduced that the globalisation of production and world markets has created a new way of political and economic engagement between countries at continental and global levels. Therefore, the ways in which economies are interconnected changes the ways in which economic policies are made. For instance, based on vertical specialisation, trade and foreign investments have become closely linked. Therefore, it is not easy to differentiate between trade strategies from policies aimed at wooing direct investment and capital flows from foreign investors. In a more and more interconnected global economy, policy-makers face challenges in safeguarding a country's specific economic interests related to trade, regulation and competition policy (Cisse, 2015).

Explaining further, Cisse $(2015$, p. 9) contended that in an increasingly interconnected global trading system, production systems have become globalised, hence the growing trade dependency. A country sells what it produces and buys what it lacks from another country. Thus, globalisation of production is directly connected with the globalisation of trade. Without international trade, each country would have limited access to the products and commodities it lacks. Global production systems based on trade enable access to varieties of products and specialised services. They also facilitate the distribution of products across the world. Therefore, it is not out of place that the Chinese pharmaceutical companies that are engaged in the production of Ejiao penetrate Africa in search of donkey skin to augment their domestic shortfalls. Therefore, Cisse (2015) concluded that in their trade relations with China, African countries have trade deficits; even though they are endowed with resources, they failed to take advantage of rising global commodity prices. But resource exports alone, without the development of other economic sectors, are not in the long run sustainable. Generally, the composition of Africa's trade with China remains unchanged.

The imbalance of the Sino-African trade which is detrimental to raw materials production countries has been attributed as a by-product of economic globalisation. A survey found out that China's economic existence in SSA is part of its 'go out' strategy, and China-SSA cooperation is part of the globalisation. In China-SSA cooperation, some SSA enterprises find difficulties in competing with Chinese companies. Trade frictions need to be solved properly by the governments. For example, 
Maigari, A. M., Dantani, U., Yelwa, M. M. \& Ibrahim, A. (2020). Scavenging for Ejiao's raw material and the extinction of donkeys in Nigeria. Global Journal of Sociology: Current Issues. 10(2), 71-87. https://doi.org/10.18844/gjs.v10i2.5102

China committed to limit the exports of 31 categories of products to South Africa and agreed to help the compatibility of the African textile industry (Bo, 2018).

\section{Synthesis of the reviewed literature}

The inflow and outflow of manufactured goods and raw materials from African markets, legal and illegal, have impacted the continent tremendously, positively and negatively. The negative effects observed in the literature reviewed is that the donkey, which is a means of transportation for centuries before the invention of steam engines and the vehicle, is facing extinction from the surface of the earth due to development in medical sciences which requires its skin as an ingredient in the production of alternative medicine. The findings of the reviewed studies showed that the donkey is not the only animal whose demand by foreign pharmaceutical industries threatens its existence on earth. The elephant too is among the animals that are highly demanded by some Asian pharmaceutical companies for the manufacturing of alternative medicine. What is common in the literature in many African markets surveyed is that trades and bilateral agreements between the Nigerian government and it Chinese counterparts have created an avenue for the Chinese business people to transact business with little or no restrictions in many African countries. In this connection, the booming market for trading in donkey as a result of influx of Chinese buyers is an indication of China's involvement in different business transactions in Africa. For example, in 2000, Sino-African trade was estimated at 10 billion US dollars a year and as of 2018 it was roughly estimated at 200 billion US dollars.

\section{Theoretical explanation}

The main thrust of globalisation is the opening of the global markets and boundaries to ease movements and extend the free exit of business transactions. From the Marxian point of view, the penetration of foreign companies seeking raw materials to manufacture ejiao is a new form of neocolonialism, imperialist penetration and domination of the weaker countries. The major raw material needed for the manufacturing of ejiao is the skins of donkeys and they are found in large populations in North-western Nigeria. Nigeria and China have entered into different agreements with China since 1998 which gave the Chinese the leverage to invest in the oil sector, railway and commercial activities. These opened doors for the mass influx of Chinese merchants and construction firms to Nigeria and other African countries to carry out lucrative contracts and trades. These agreements have solidified the Chinese presence in the continent whose effects are felt by one of the means of transportation that African civilisation relies upon for centuries-by donkey. A reasoned critique of globalisation and China's poaching for donkey skin indicates that business corporations get exorbitant profits through direct trade with African countries, which in most occasions, Chinese merchants eliminate middlemen in their transactions and they carry out direct trading with the producers or owners. These international corporations maintain and explore the links with their nation states and headquarters to penetrate underdeveloped economies. They also adopt the world market as the reference point for their activities by establishing an unprecedented internal circulation of capital, labour, inputs and technology (Katz 2001, p. 85). Furthermore, the international expansion of capital implied the parasitic predominance of financial capital along with the creation of monopolies that stifled free trade (Lenin, 1973).

Similarly, because the Chinese demands for donkeys are unprecedented in the 21st century, the Chinese merchants from 2016 to 2019 focused their attention on Africa to source for donkeys and the export DHG, which was attributed to the increased promotion of DHG products and its impacts on the human system. The export of DHG was to make profit by the merchants on one hand and meet the health needs of Chinese at home or those who resides in foreign countries on the other. To substantiate this, China's Customs Information Network stated that the export of DHG pills in the first 10 months of 2017 has reached $\$ 100$ million (Humane Society International, 2018). Therefore, the trade between African countries and China is a detriment to the African countries. This is evident in 
the decrease in the population of donkeys and by implication affects an old means of transportation (donkey) of most rural dwellers which is considered as a beast of burden on one hand, and on the other there is a palpable fear that the donkey would become extinct.

\section{Methodology}

This paper adopted a qualitative research type. The phenomenological research design was adopted because it suited the nature of this study, which focused on the understanding of a phenomenon and lived experiences. Also, it is appropriate in in-depth description of a phenomenon where the best method of primary data collection is in-depth Interview and key informant interview. Data were obtained from fieldwork in some selected villages in Zamfara, Sokoto and Kebbi states where there were large weekly donkey markets. Some of the areas are located on the border of Nigeria and the Niger Republic which is an arid land characterised by low rainfall, and in these arid lands the donkey is still the most common means of transporting goods and humans. Through the snowballing technique, the researchers identified participants for the interviews. There were selected because they had ample knowledge and experience on the phenomenon investigated. A total of $20 \mathrm{KII}$ and 5 in-depth interviews (IDI) with donkey owners, users and farmers in the donkey markets of Dauran village, Zurmi Local Government Area (LGA) of Zamfara State were conducted. In Sokoto and Kebbi States, Rabah LGA and Kalgo LGA, respectively, were selected. Farmers, users and marketers were purposively selected for the interviews based on their familiarity with the phenomena investigated. The aim was to collect rich and in-depth data from the rural dwellers directly involved in the reading of donkey, donkey husbandry and using it for conveying loads. For the instruments of data collection, KII and IDI were developed by the researchers based on the objectives of the study. Each interview which was conducted in Hausa language lasted for more than 30 minutes with each research participant, which was recorded with a tape recorder in addition to book for noting important points and physical observations. The results were presented using a matrix table and narrative style of data presentation in qualitative study (Table 1).

\section{Data presentation and analysis}

Below is the presentation of qualitative data from the fieldwork.

\section{The importance of donkeys in the area}

Table 1. Matrix table: summary of responses

\begin{tabular}{lcc}
\hline \multicolumn{1}{c}{ Importance of donkeys } & Frequency & Percentage \\
\hline Agricultural/transportation & 10 & 50 \\
Social status & 5 & 25 \\
Herding to sell & 5 & 25 \\
Total & 20 & 100 \\
\hline
\end{tabular}

The results from the interviews indicate that the donkey is a beast of burden in arid areas like the north-western part of Nigeria. This is because the donkey can adapt to the hot weather of the Sokoto, Katsina Kebbi and Zamfara states. On this basis, they are an important means of transportation in rural areas and serve different agricultural purposes for farmers. The life of the people in the areas are attached to the domestication of animals, including donkeys, which are kept as an asset to be sold when there is a financial need in the family. There is also a category of people who use the donkey to carry loads and other goods for commercial purpose. A participant during KII stated that for centuries the donkey was used for various purposes by their forefathers and still the animal serves the same purposes and improves the livelihood of the people. 
Maigari, A. M., Dantani, U., Yelwa, M. M. \& Ibrahim, A. (2020). Scavenging for Ejiao's raw material and the extinction of donkeys in Nigeria. Global Journal of Sociology: Current Issues. 10(2), 71-87. https://doi.org/10.18844/gjs.v10i2.5102

A participant and donkey herder in Dauran Village, Zurmi LGA, Zamfara state during the IDI narrated that:

We inherited the culture of transporting farm produce in pre and post-harvest periods using Donkey. Possession of Donkey was synonymous with wealth in our villages. It is rare to find a House without a Donkey or Cow. We are all farmers in this village, even those who are civil servants, they still have those animals for farm use.

Another participant in Kalgo LGA, Kebbi state during the IDI session stated that:

Even though in Islam it is prohibited to eat the meat or drink milk of a Donkey, we do keep them as an economic asset like cattle. Apart from being an asset, it serves more purpose than a Cow, because it convey heavy loads, like sand for building houses for people which serves as a source of income for me. But now that the buyers are coming from Southern Nigeria, they offer Donkey's owners huge amount money that is irresistible. Now, we have people taking the skin to China, they are going to different villages, buying Donkeys at high prices.

Similarly, a donkey marketer in Rabah LGA, Sokoto recounted his experience of trading donkeys. He recounted that:

I have been into this business for the past 40 years. Yes! Majority of the people here come to the market to purchase for farm use, conveying loads in the village for commercial purpose or both. There are some who rear them for the purpose of selling, like us. I use to keep at least twenty to forty Donkeys in my house because buyers often come to me in need of them. There are other wealthy people in this area who domesticate Donkeys like cattle just to sell it.

Additionally, a participant in Dauran, Zamfara state stated during the IDI that:

Aside going to farm, conveying farm inputs to the farm and produce to House after harvest, I use my Donkey for transportation. Any journey that is less than $30 \mathrm{~km}$, I used to embark it on my Donkey. It is economical than Car and Motorcycle because one do not need to buy fuel or repairs it. You see, Donkey do not require energy to ride like Bicycle that is the reason even old people who are above 70 years ride Donkey in Dauran and other villages. All you need to do is to provide stalk and water for the Donkey before the commencement of the journey.

A participant in Kalgo, Kebbi state during the KII explained that apart from the owners of donkeys, there are segment of the population who do not own donkeys but are benefiting from it. This category of donkey users are the ones who ride the donkeys to transports goods or loads in exchange for money. He succinctly stated that:

Using Donkey for transporting goods or loads especially here that the roads are bad, vehicle cannot pass, Donkey has become only means of transporting heavy loads. Our youth who are jobless use to go and rent Donkey from the owners in the morning and return them to the owners in the evening. We have many youth who rely on this as their means of sustenance or income.

It could be deduced from the findings that donkeys are kept for different in reasons in Northern Nigeria; among the reasons for the rearing or domestication of donkeys is that it has an economic and social impact on the livelihood of rural dwellers. The qualitative data further demonstrate how rural people value the donkey as an indicator of social status, means of transportation and an economic asset. This correlates with the findings of Geiger et al. (2020) in a study conducted on the importance of working donkeys in rural areas of Ethiopia. The study found that donkeys are an important support in rural, peri-urban and urban settings through the creation of economic security, independence and participation in local saving schemes. In addition, donkeys provide social status, empowerment to 
marginalised groups, such as women and the very poor, and provide a sense of companionship. This implies that donkeys are not mere means of transportation and farm equipment, but an economic asset which determines one's location in the social ladder. In between herders and users for agricultural purposes lies those who ride the donkey as an occupation in rural areas and source of income.

Table 2. The shrinking population of donkeys

\begin{tabular}{lcc}
\hline \multicolumn{1}{c}{ Causes } & Frequency & Percentage \\
\hline Disease & 5 & 25 \\
Sales & 10 & 50 \\
Poaching & 5 & 25 \\
Total & 20 & 100 \\
\hline
\end{tabular}

Table 2 summarises the recurring responses from the interviews conducted with the research participants. Five out of the 20 participants attributed the decrease in the population of donkeys to diseases that has been killing them in the areas, while five participants pointed out that is the activities of poachers that has been affecting the population of donkeys. However, a significant proportion of the participants averred that it is the sales of donkey, as a result of increased number of buyers, that have affected negatively the population of donkeys.

A participant during the IDI in Kalgo, Kebbi state explained that:

There is a hoot, liver and disease that has been killing our Donkeys. We lacked Veterinary services in this village. We only give them traditional medicine is not effective, within 2-3 days of the sickness, you will your Donkey is death. When the season of disease come, ten Donkeys can die in a day. This is the reason why their number is decreasing.

During the IDI, another participant in Rabah, Sokoto state observed that:

Of course disease has been killing our Donkeys and till date, Government has not shown any sign rendering assistance to the owners. You see! The buyers of Donkey has increased from Southern Nigeria and Niger Republic. We heard that the Government of Niger Republic has banned the sales of Donkey that is why they are running to boarder here to buy it. We are aware that most of the buyers now are not the usual customers who used to come from Eastern and Southern Nigeria. You know, their demand is for normal consumption but the ones coming from Niger Republic and other parts of Northern Nigeria, they are agents of some Chinese merchants who want buy and remove the skin, then take it to China.

In an IDI in Dauran, Zamfara state, a participant narrated that:

Since the ban on the sales of Donkey in Niger Republic and buyers has been trooping our markets and villages, looking for Donkeys. Thieves have been stealing Donkeys daily in this villages. Before the increase in the number of buyers, we hardly experience a missing Donkey. We often found death bodies of our Donkey dumped in a bush along Zurmi road in the morning. They are conniving with Butchers who specialised in removing Skin of cattle to remove the Skin for them. Yes! They are after the skin not meat, the skin is more valuable than the meat to them. We heard that the Skin only need the Skin not the meat.

A participant who has been in the business of selling donkeys in Kalgo, Kebbi State, during the KII recounted that:

The population of Donkey in Kebbi State has decreased perhaps, as a result of increasing demands from buyers and theft from thieves. Before, on a Market Day like this, averagely, you can see at least two hundred Donkeys brought by sellers from different parts of Northern Nigeria and Niger Republic. Sellers find it tempting the price per Donkey offered 
by the Chinese or their Agents. Some of their Agents come from different parts of Nigeria and China. Some owners of the Donkey see the money as means to become wealthy not knowing they would 1 day realised the Donkeys have finished. In Nigeria, there is no restriction regarding trading in Donkey. If it is those who come from Cross-River State or Enugu State to buy, that is understandable, they come monthly and it is mainly for consumption, they are not only after the skin but including the meat and milk.

It could be deduced from the above findings that there is pressure from the global market including domestic buyers for the consumption in Nigeria of donkeys. Therefore, foreign and internal demands for consumption and raw material have outstripped the reproduction capacity of donkeys in Nigeria hence the population has been dropping. The result further revealed that increases in the number of buyers have led to the increase in the price of donkeys; this enticed majority of the owners of the donkeys to sell them. Similarly, the increase in price because of the arrival of Chinese agents has prevented donkey users from buying it for rearing to increase its population. Furthermore, buyers from Eastern and Southern Nigeria find the new price for donkeys exorbitant, hence they could not afford to buy and sell it in their areas. Additionally, the activities of poachers have been affecting the population of donkeys since the price is attractive. This implies that the population of donkeys is at risk because of the increased price in the market, buyers and poachers. Majority of the villager who are used to the domestication of donkeys have stopped because of the increase in price, disease and thefts. This is line with the findings of Gichure, Onono, Wahome, and Gathura (2020) who found that some of the major factors that threaten the existence of donkeys in Africa are theft for slaughter, disease incidence, road accidents and malicious cutting. Similarly, Khaleel et al. (2020a) also found that the population of donkeys were drastically decreasing due to the overexploitation for its hide and industrialisation in Northern Nigeria.

\section{Discussion of major findings}

Domestication of donkeys for agricultural needs and transportation has been a century-long practice in the Northern Nigeria states that are located in the desert areas. The history of the existence of donkeys in the areas studied is interlinked with the history of the existence of human beings in the areas. Donkeys are valuable as a means of transportation because they have the ability to withstand the temperature of the desert, as only a camel can live in the desert better than it. Its adaptability to the weather and geographical terrain which is mostly sandy made it a coveted domestic animal among the inhabitants before the scientific breakthrough that led to the manufacturing of cars. This is corroborated by the conclusions of Camillo et al. (2018), Pearson and Ouassat (2000) and Rossel et al. (2008) who stated that about 6,000-7,000 ago, donkeys were domesticated in the north-eastern part of Africa and played a vital role in the growth and development of human being populations as well as in trade practices in the ancient world. They further stated that that donkey can thrive better under difficult environmental conditions, such as high temperature, low rainfall and low quality feeds, as a result of certain genetic and morphological changes that occur during its domestication.

The findings of a study found that diseases are among the factors causing a lot of deaths among donkeys in Northern Nigeria. The participants stated that there is lack of veterinary services to treat donkeys that are sick. This is line with the findings of Matlhola and Chen (2020), which found that diseases are among the factors that reduce the population of donkeys in developing countries where drugs and veterinary services are scarce or non-existent.

Similarly, it could be deduced from the findings that the donkey continues to serve the purposes it served for centuries, despite the innovation of modern farm equipment and efficient means of transportation. However, development in the manufacturing of alternative medicine in Asia has necessitated the need for raw materials for the production of ejiao for which donkey skin is the most coveted part. The demands have not only increased the monetary value of the skin of donkeys but also portended a bleak future where the donkey would be wiped out from the face of the earth. The 
farmers, local transporters and herders of donkeys are faced with the scarcity of the animal due to the high demands from foreigners which has skyrocketed the price beyond the purchasing power of villagers who use it for transporting goods, people and animal husbandry.

The findings also revealed that the decrease in the population has some social effects in the areas. First, it has rendered jobless people, especially youth, who rely on it as a source of income through carrying goods, people and heavy loads in rural areas where most of the roads are bad and vehicles cannot ply. Additionally, the demands for skin have made donkeys expensive beyond the reach of Nigerians who consume its meat. Another implication for the exportation of donkeys and its decreasing population is that domestic merchants or traders would also be rendered jobless due to the shortage in supply of the animal. Therefore, effects of the decrease in the population of donkeys or increase in price would affect agricultural activities, economic activities and rural livelihood. This correlates with the findings of Binda's (2019) study conducted in South Africa which showed that buying donkey skin is also affected by the increasing presence of Chinese merchants. The researcher stated that within South Africa, rural communities use working animals instead of or combined with mechanisation of farming and chores. Development progress may have evaded these areas but it impacts them through globalisation and China's expanded market power. The burgeoning market for ejiao, a popular traditional Chinese medicine made from boiling donkey hides is a growing issue. Wealthier Chinese consumers, a stalled South African rural population who missed developmental benefits plus increasing economic and political engagements between the two countries, allow a monopolised and often exploitative market for donkeys. Politicians are eager to partner with Chinese ejiao retailers despite the resulting decimation of donkey populations in some areas of Africa and the destruction of livelihoods.

The findings of the study have established that there is no law in Nigeria which regulates the activities of trading donkeys at the time countries like Niger Republic and Burkina Faso in West Africa have enacted laws that prohibit the exportation of donkeys to save the animals from extinction. Donkey owners and users are left to the mercy of global trade and wealthy merchants from China and other Asian countries, who have been exploiting the existing poverty in the areas by offering high price for the donkeys beyond what the purchasing power of the domestic consumers of donkeys. This correlates with the findings of Khaleel (2020b) regarding the poor regulation of animal welfare in Nigeria. The lack of law enforcement, poor management and animal welfare in abattoirs to protect pregnant animals are among few factors responsible for an increase in incidences and decrease in the population of some animals in Nigeria. The findings are also corroborated by Altherr (2020) who states that the use of wildlife in traditional Chinese medicine has repeatedly come under criticism, especially given the increasing number of species being driven to extinction. The Convention on International Trade in Endangered Species of Wild Fauna and Flora has the mandate to regulate trade in wildlife on an international level; however, on a national level it is the duty of individual governments.

\section{Conclusion}

The study found that despite being the source of raw material for the production of ejiao, there is no single manufacturing industry that manufactures ejiao in Nigeria. In fact, the there is little awareness about the existence of the product in areas where they supply donkey hide to China. Additionally, the exportation of donkeys to China has rendered people who rely on donkeys to earn income jobless. This is because majority of the owners had already sold them to Chinese merchants or their agents. Also, for people in southern and eastern parts of Nigeria who eat donkey's meat and drink its milk, it is expensive beyond the purchasing power of the middle-income earners in the areas. For farmers, the disappearance of the donkey reduced soil fertility because donkey's dung contains some nutrients that add soil fertility whose absence affects yield in the farms.

The need for alternative medicine in China has revived the importance of ejiao to address diseases that orthodox medicine proved ineffective to cure. Belief in the value and importance alternative medicine led to the increase in the demands for ejiao in China and other parts of Asia. The increase in 
the number of customers has propelled pharmaceutical industries that manufacture ejiao to increase production to satisfy the demands. The unification of the world in trade, communication and governmental relations has opened Nigerian markets for the Chinese merchants to search for the raw materials for the production of ejiao. The same is found in some African countries, like Niger Republic, where different trades and bilateral agreements with China have opened the door for the Chinese marketers to penetrate.

Therefore, the soaring increase in the demand and production of ejiao in China has become a threat to an animal which served different civilisation in Northern Nigeria prior to slave trade and colonialism. The implications of slaughtering or selling donkeys for Ejiao is that the next generation of people in Northern Nigeria would grow up without knowing the donkey, its importance in transportation and an indicator of social status in the society. People in rural areas without roads or vehicles would continue to suffer in transporting goods or loads that were hitherto transported on donkeys. Additionally, people who ride donkeys for commercial purposes have become unemployed hence the increased rate of poverty in the already impoverished areas. These are some of the effects of globalisation between developed countries and developing countries which have not changed for decades; countries like Nigeria still produce raw materials, which will have detrimental effects on the soil, people and development of society. Raw materials are taken from Africa to China, providing employment and income for their citizens and government, while here in Nigeria, people who sold their donkeys because of the irresistible price, have further plunged into poverty as a result of the declining population of animals. Similarly, people who are neglected by the government in rural areas due to the absence of roads and other public utilities are subjected to further hardship in transporting their heavy goods now that the donkeys that used to assist them are scarce.

\section{Recommendations}

i) Therefore, a pragmatic policy should be initiated and implemented by governmental and nongovernmental organisations to control the influx of foreign merchants and poachers of donkeys into rural areas in order to save the animal from extinction. In doing so, the policy would avert impending suffering that rural dwellers could face because majority of them depend on it for transportation, agricultural use and domestication as an asset. This underscores the importance of the donkey in north-western Nigeria and neighbouring communities on the border between Nigeria and the Niger Republic.

ii) The government should ban the exportation of live donkeys or hides as part of the measures to stop their population from further declining.

iii) The government should provide veterinary services to rural areas where donkeys lack preventable and treatable diseases.

iv) The government should initiate a sensitisation programmes in rural areas where people domesticate donkeys on the implications of selling donkeys to exporters.

\section{References}

Altherr, S. (2020). Aktuelle artenschutzprobleme im kontext der traditionellen chinesischen medizin. Chinese Medicine, 35, 113-128.

BBC. (2016). Niger bans the export of donkeys after Asian demand. Retrieved from https://www.bbc.com/ news/world-africa-3728681

Bennett, R. \& Pfuderer, S. (2019). Demand for donkey hides and implications for global donkey populations. A Discussion paper prepared for presentation at the 93th Annual Conference of the Agricultural Economics Society, University of Warwick, Coventry, UK. 
Bennett, R. \& Pfuderer, S. (2020). The potential for new donkey farming systems to supply the growing demand for hides. Animals, 10(718), 1-22.

Binda, K. (2019). A Donkey's worth in South Africa: domestic laborer or export product; socioeconomic impacts of china's skin trade on South African donkey owners (Unpublished master's thesis). Faculty of Social Sciences. Institutes of Economic \& Political Studies. Charles University in Prague, Prague, Czechia, pp. 1115.

Brooke USA. (2018). Campaign to ban the sale of Ejiao in the United States. Retrieved from https://static1.squarespace.com/static/5a300859010027bc692da861/t/5f9b27f043fe5e1106e702ef/160 4003825238/Ejiao+One+Pager.pdf

Camillo, F., Rota, A., Biagini, L., Tesi, M., Fanelli, D. \& Panzani, D. (2018). The current situation and trend of donkey industry in Europe. Journal of Equine Veterinary Science, 65(1), 44-49.

Carder, G., Ingasia, O., Ngenoh, E., Theuri, S., Rono, D. \& Langat, P. (2019). The emerging trade in donkey hide: an opportunity or a threat for communities in Kenya? Agricultural Sciences, 10, 1152-1177.

Carmignani, F. \& Chowdhury, A. (2012). The geographical dimension of the development effects of natural resources. Environmental and Resource Economics, 52(4), 479-498.

Celermajer, D. \& Wallach, A. (2019). The fate of the illegible animal: the case of the Australian wild donkey. Animal Studies Journal, 8(2), 229-258.

Chen, W. \& Nor, R. (2017). A rebalancing act for China and Africa: the effects of China's rebalancing on SubSaharan Africa's trade and growth. Washington, DC: International Monetary Fund, Publication Services.

Cisse, D. (2015). Globalisation and sustainable Africa-China trade: What role play the African regional organisations? The Nordic African Institute. Occasional Paper, pp. 1-31.

Donkey Sanctuary. (2017). Under the skin report. Retrieved December 21, 2017, from https:// www.thedonkeysanctuary.org.uk/under-the-skin/full-report

ECONEWS Portal. (2018). Donkeys in Africa doomed by china. Retrieved from https://ecoterra.info/ index.php/en/654-donkeys-in-africa-doomed-by-china

Geiger, M., Hockenhull, J., Buller, H., Tefera, E.G., Getachew, M., Burden, F.A. \& Whay, H.R. (2020). Understanding the attitudes of communities to the social, economic, and cultural importance of working donkeys in rural, peri-urban, and urban areas of Ethiopia. Frontiers in Veterinary Science, 7(60), 1-13.

Gichure, M., Onono, J, Wahome, R. \& Gathura, P. (2020). Analysis of the benefits and production challenges of working donkeys in smallholder farming systems in Kenya. Veterinary World, 13(11), 2346-2352.

Global Initiative against Transnational Organized Crime. (2020). Civil society observatory of illicit economies in eastern and southern Africa. Risk Bulletin, 1-24.

Golley, J. \& Jaivin, L. (2018). China story yearbook 2017: prosperity. Canberra, Australia: ANU Press.

Humane Society International. (2018). The production, raw material resources and consumption of donkey-hide gelatin (Ejiao). Investigative Report.

Jackson, A. (2019). Donkey poaching: a growing global threat. Gold Coast, Australia: Australian Veterinary Association Conference.

Khaleel, A. G., Lawal, L. A., Mudassir, N., Hassan, A. M., Abdu, M. I., Salisu, N. \& Kamarudin, A. S. (2020a). Morphometric characterization of Donkeys (Equus asinus) in D/Kudu Kano State for Selective Breeding and Genetic Conservation. Journal of Agrobiotechnology, 11(2), 12-21. 
Khaleel, A. G., Nasir, M., Salisu, N., Abdullahi, A.Y., Saidu, S.S., Saleh, A. \& Ahmad-Syazni. K. (2020b). Abattoirs: a hidden centre for livestock genetic resources loss in Nigeria. Malaysian Journal of Applied Sciences, 5(2), $1-16$.

Khan, S. A., Baye, F. M. \& Tange, G. K. (2009). The impact of China-Africa trade relations: Case study of Cameroon. In-depth country case study on China-Africa trade relations. Nairobi, Kenya: Final Report submitted to the African Economic Research Consortium (AERC).

Kuo, L. (2017). The donkeys Kenyan families need to survive are heading to china for medicine promising longer life. Equine Exports.

Matlhola, D. M. \& Chen, R. (2020). Telecoupling of the trade of donkey-hides between botswana and China: challenges and opportunities. Sustainability, 12, 17-30.

National Prosecuting Authority (NPA South Africa). (2017). Media statement: NPA obtains a preservation order for 2921 Donkey Hides. Retrieved December 6, 2019, from www.npa.gov.za

Pearson, A. \& Ouassat, M. (2000). A guide to live weight estimation and body condition scoring of donkeys. Midlothian, Scotland: Centre for Tropical Veterinary Medicine University of Edinburgh.

Rossel, S., Marshall, F., Peters, J., Pilgram, T., Adams, M. D. \& O'Connor, D. (2008). Domestication of the donkey: timing, processes, and indicators. Proceedings of the National Academy of Sciences, 105, 3715-3720.

Supplier Discovery. (2021). Made in China. Retrieved from https://www.made-in-china.com/manufacturers/ ejiao-companies.html.

Talla, R. T. \& Song, I. W. (2014). Animal transport in the early indigenous market economy of northern Nigeria. International Journal of Humanities Social Sciences and Education, 7, 148-156.

Vira, V., Ewing, T. \& Miller, J. (2014). Out of Africa: mapping the global trade in illicit Elephant's Ivory. Born Free, 3-4.

Wallach, A. D., Lundgren, E. J., William, J., Ripple, W. J. \& Ramp, D. (2018). Invisible megafauna. Conservation Biology, 32(4): 962-965.

World Veterinary Association Fact Sheet. (2018).

World Wide Fund for Nature/Dalberg. (2012) Fighting illicit wildlife trafficking: a consultation with governments. Gland, Switzerland: WWF International. 